\title{
Hydrogen Bonding Between Tetrahydrocannabinol and Vitamin E Acetate in Unvaped, Aerosolized, and Condensed Aerosol E-Liquids
}

\author{
Adam Lanzarotta, Travis M. Falconer, Rick Flurer and Robert A. Wilson
}

Forensic Chemistry Center, Office of Regulatory Science, Office of Regulatory Affairs, U.S. Food \& Drug Administration, Cincinnati, OH USA 45237

The material contained herein includes what is tabulated below.

\begin{tabular}{|c|c|}
\hline Supplemental information & Description \\
\hline Table S1 & $\begin{array}{l}\text { Infrared band assignments for the THC, VEA and THC:VEA hydrogen } \\
\text { bonded complex }\end{array}$ \\
\hline Figure $\mathrm{S} 1$ & $\begin{array}{l}\text { Full scan mass spectrum of THC control sample (same spectrum as } \\
\text { Figure } 5 b \text { ). }\end{array}$ \\
\hline Figure S2 & 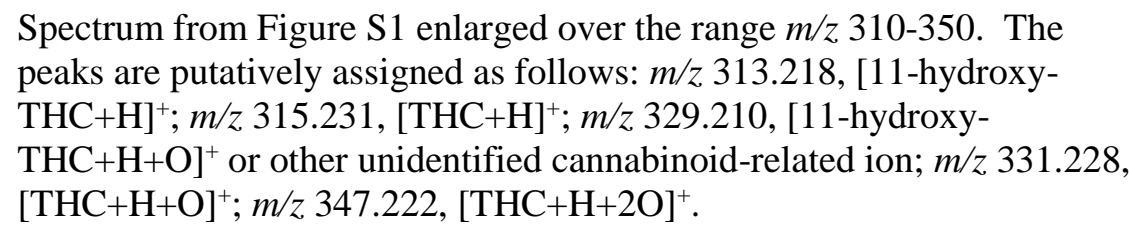 \\
\hline Figure S3 & $\begin{array}{l}\text { Full scan mass spectrum of VEA control sample (same spectrum as } \\
\text { Figure } 5 \mathrm{c} \text { ). Note that } m / z 430.381 \text { is a fragment of VEA. }\end{array}$ \\
\hline Figure S4 & $\begin{array}{l}\text { Spectrum from Figure } \mathrm{S} 3 \text { enlarged over the range } \mathrm{m} / \mathrm{z} 467-510 \text {. The } \\
\text { peaks are putatively assigned as follows: } \mathrm{m} / z 472.390, \\
{\left[\mathrm{VEA}+\mathrm{NH}_{4}-\mathrm{H}_{2} \mathrm{O}\right]^{+} ; \mathrm{m} / z 473.400,[\mathrm{VEA}+\mathrm{H}]^{+} ; \mathrm{m} / z 490.424,} \\
{\left[\mathrm{VEA}+\mathrm{NH}_{4}\right]^{+} ; \mathrm{m} / z 504.378,\left[\mathrm{VEA}+\mathrm{O}_{2}\right]^{+\cdot} \text {. }}\end{array}$ \\
\hline Figure S5 & $\begin{array}{l}\text { Spectrum from Figure } \mathrm{S} 3 \text { enlarged over the range } \mathrm{m} / \mathrm{z} \text { 940-970. The } \\
\text { peaks are putatively assigned as follows: } \mathrm{m} / z \text { 945.795, }[2 \mathrm{VEA}+\mathrm{H}]^{+} ; \mathrm{m} / \mathrm{z} \\
962.822,\left[2 \mathrm{VEA}+\mathrm{NH}_{4}\right]^{+} \text {. }\end{array}$ \\
\hline Figure S6 & $\begin{array}{l}\text { Full scan mass spectrum of suspect THC and VEA-containing sample } \\
\text { (same spectrum as Figure 5a). Peaks are putatively assigned as above, } \\
\text { except for } m / z 787.627 \text { (see Figure S7). }\end{array}$ \\
\hline Figure S7 & $\begin{array}{l}\text { Spectrum from Figure S6 enlarged over the range } m / z \text { 780-825. The } \\
\text { peaks are putatively assigned as follows: } m / z \text { 787.627, [THC+VEA+H }]^{+} \text {; } \\
m / z \text { 803.622, }[\mathrm{THC}+\mathrm{VEA}+\mathrm{H}+\mathrm{O}]^{+} ; \mathrm{m} / z \text { 818.629, }\left[\mathrm{THC}+\mathrm{VEA}+\mathrm{O}_{2}\right]^{+} \text {. }\end{array}$ \\
\hline Figure S8 & $\begin{array}{l}\text { MS/MS spectra obtained with collision energy of } 30 \mathrm{eV} \text { and precursor } \\
\text { isolation width of } \pm 0.5 \text { Da: a) precursor is [VEA }+\mathrm{H}]^{+} \text {; b) precursor is } \\
{[\mathrm{THC}+\mathrm{VEA}+\mathrm{H}]^{+} \text {. The spectrum in b) shows that the THC+VEA ion }} \\
\text { dissociates into THC }(\mathrm{m} / \mathrm{z} 315.232 \text {, cf. Figure } \mathrm{S} 2) \text { and VEA }(\mathrm{m} / \mathrm{z} \\
473.395 \text {, cf. Figure } \mathrm{S} 4 \text {, and } \mathrm{m} / \mathrm{z} 431.383 \text { and } 207.101 \text {, cf. spectrum a) } \\
\text { below). }\end{array}$ \\
\hline
\end{tabular}




\begin{tabular}{|l|l|}
\hline Figure S9 & $\begin{array}{l}\text { Full scan mass spectrum of aerosolized suspect THC and VEA- } \\
\text { containing sample (same spectrum as Figure 5d). Peaks are assigned as } \\
\text { above. }\end{array}$ \\
\hline Figure S10 & $\begin{array}{l}\text { Spectrum from Figure S9 enlarged over the range } \mathrm{m} / \mathrm{z} \text { 780-825. The } \\
\text { peak assignment is the same as Figure } \mathrm{S} 7(\mathrm{~m} / \mathrm{z} \text { 787.627, } \\
{[\text { THC+VEA+H }]^{+} \text {; additionally labeled peaks are isotopes of this }} \\
\text { complex). }\end{array}$ \\
\hline
\end{tabular}

Table S1. Infrared band assignments for the THC, VEA and THC:VEA hydrogen bonded complex.

\begin{tabular}{lccc}
\multicolumn{1}{c}{ Band assignment } & $\begin{array}{r}\text { THC } \\
\left(\mathrm{cm}^{-1}\right)\end{array}$ & $\begin{array}{c}\text { VEA } \\
\left(\mathrm{cm}^{-1}\right)\end{array}$ & $\begin{array}{c}\text { THC:VEA } \\
\left(\mathrm{cm}^{-1}\right)\end{array}$ \\
\hline OH stretching & 3394 & - & 3449 \\
$\mathrm{CH}_{3}$ antisymmetric stretching & 2959 & 2951 & 2953 \\
$\mathrm{CH}_{2}$ antisymmetric stretching & 2927 & 2925 & 2926 \\
Ester C=O stretching & - & 1758 & 1758 \\
$\mathrm{C}=\mathrm{O}$ stretching (due to hydrogen bond) & - & - & 1736 \\
$\mathrm{C}=\mathrm{C}$ stretching & 1623 & - & 1623 \\
$\mathrm{C}=\mathrm{C}$ stretching & 1557 & - & 1579 \\
C-C-O stretching (due to hydrogen bond) & - & - & 1228 \\
Ester acetate C-C-O stretching & - & 1205 & 1209
\end{tabular}


Figure S1. Full scan mass spectrum of THC control sample (same spectrum as Figure 5b).

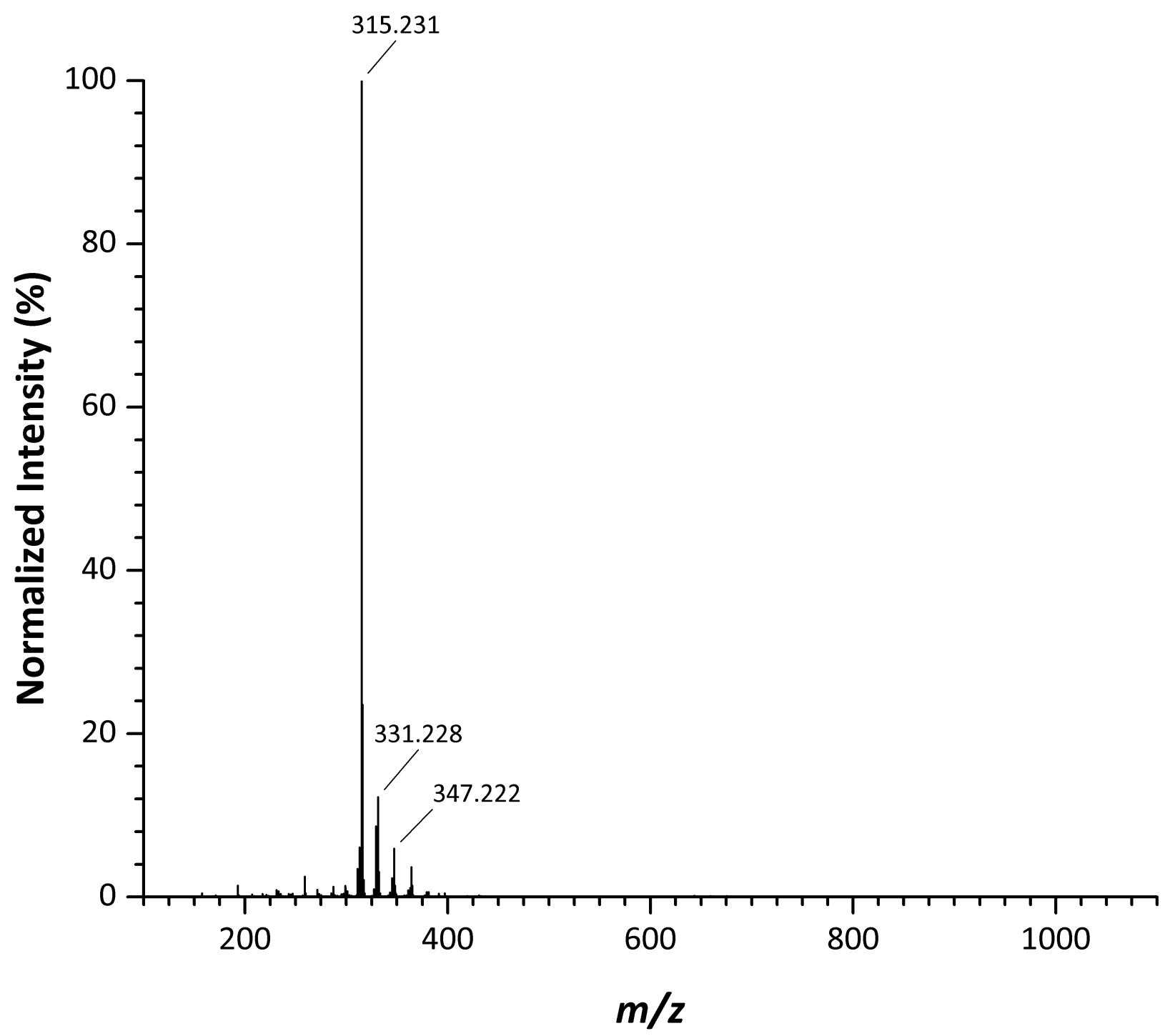


Figure S2. Spectrum from Figure S1 enlarged over the range $m / z$ 310-350. The peaks are putatively assigned as follows: $m / z$ 313.218, [11-hydroxy-THC+H] $]^{+} ; \mathrm{m} / z$ 315.231, [THC+H] ${ }^{+} ; \mathrm{m} / z$ 329.210, [11hydroxy-THC $+\mathrm{H}+\mathrm{O}]^{+}$or other unidentified cannabinoid-related ion; $m / z 331.228,[\mathrm{THC}+\mathrm{H}+\mathrm{O}]^{+} ; \mathrm{m} / z$ 347.222, [THC+H+2O $]^{+}$.

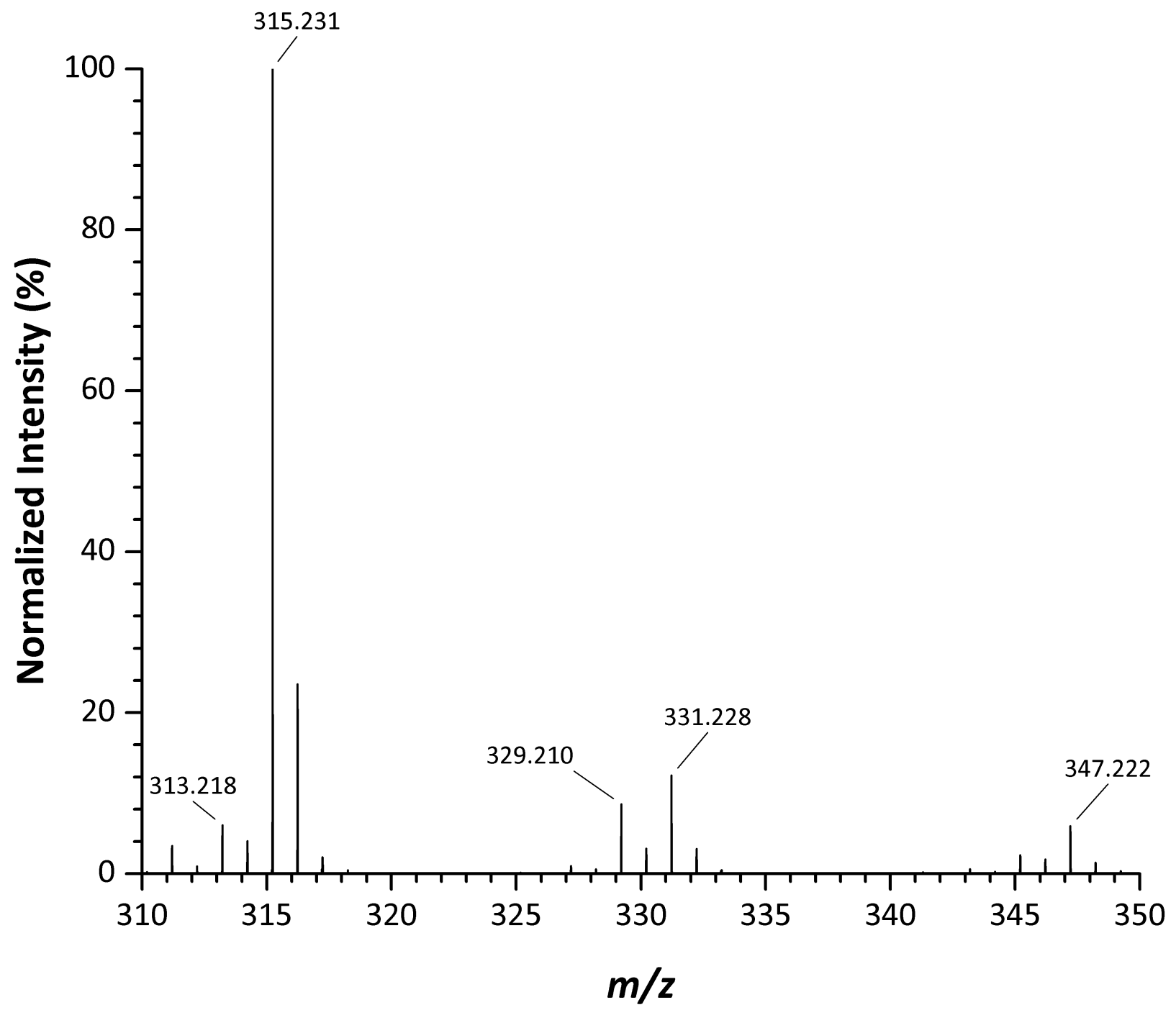


Figure S3. Full scan mass spectrum of VEA control sample (same spectrum as Figure 5c). Note that $\mathrm{m} / \mathrm{z}$ 430.381 is a fragment of VEA.

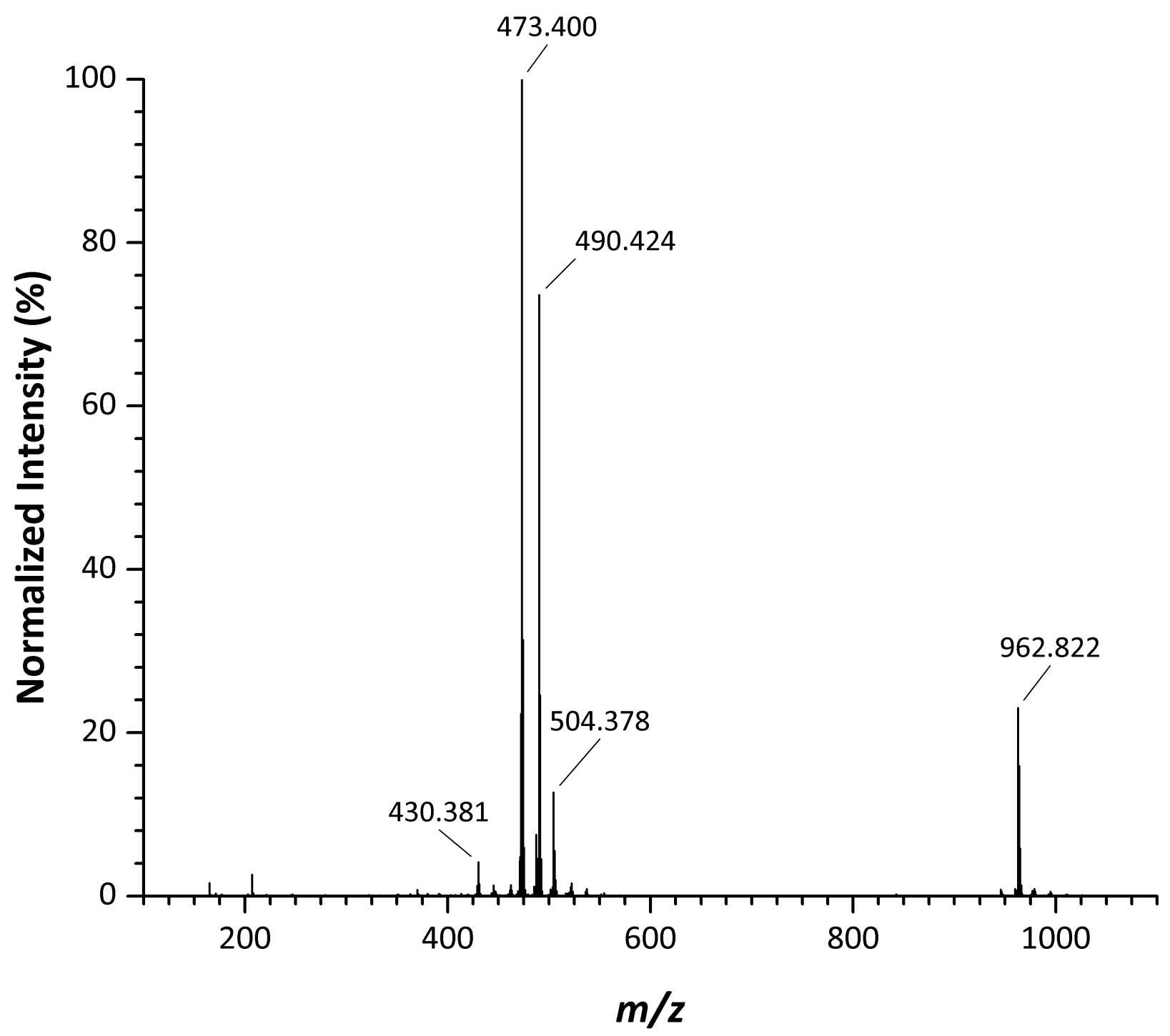


Figure S4. Spectrum from Figure S3 enlarged over the range $m / z$ 467-510. The peaks are putatively assigned as follows: $m / z$ 472.390, [VEA+NH $\left.{ }_{4}-\mathrm{H}_{2} \mathrm{O}\right]^{+} ; m / z$ 473.400, [VEA+H] ${ }^{+} ; m / z$ 490.424, $\left[\mathrm{VEA}+\mathrm{NH}_{4}\right]^{+} ; m / z, 504.378,\left[\mathrm{VEA}+\mathrm{O}_{2}\right]^{+}$.

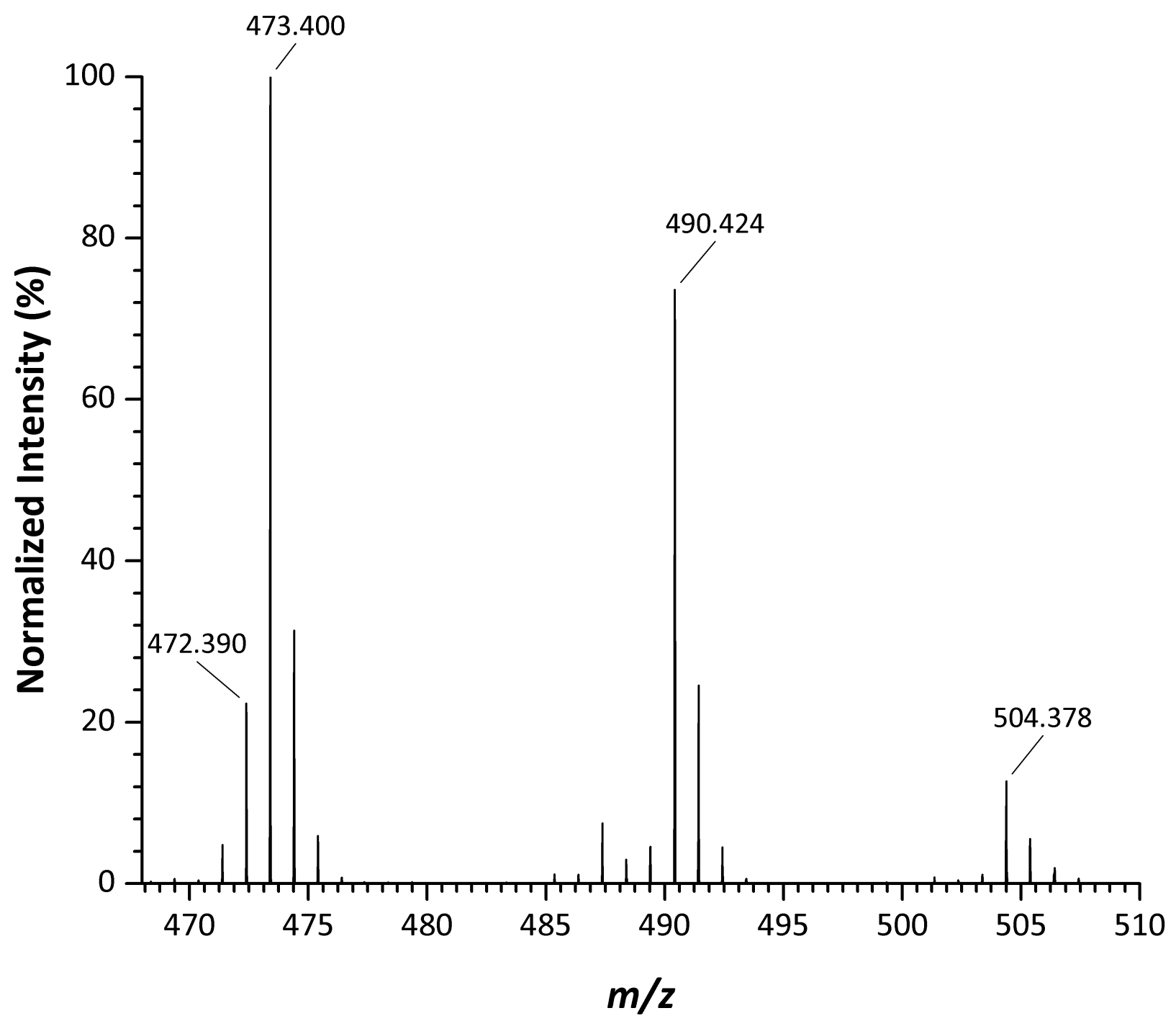


Figure S5. Spectrum from Figure S3 enlarged over the range $m / z$ 940-970. The peaks are putatively assigned as follows: $m / z$ 945.795, [2VEA+H] $]^{+} ; m / z$ 962.822, [2VEA+NH$]^{+}$.

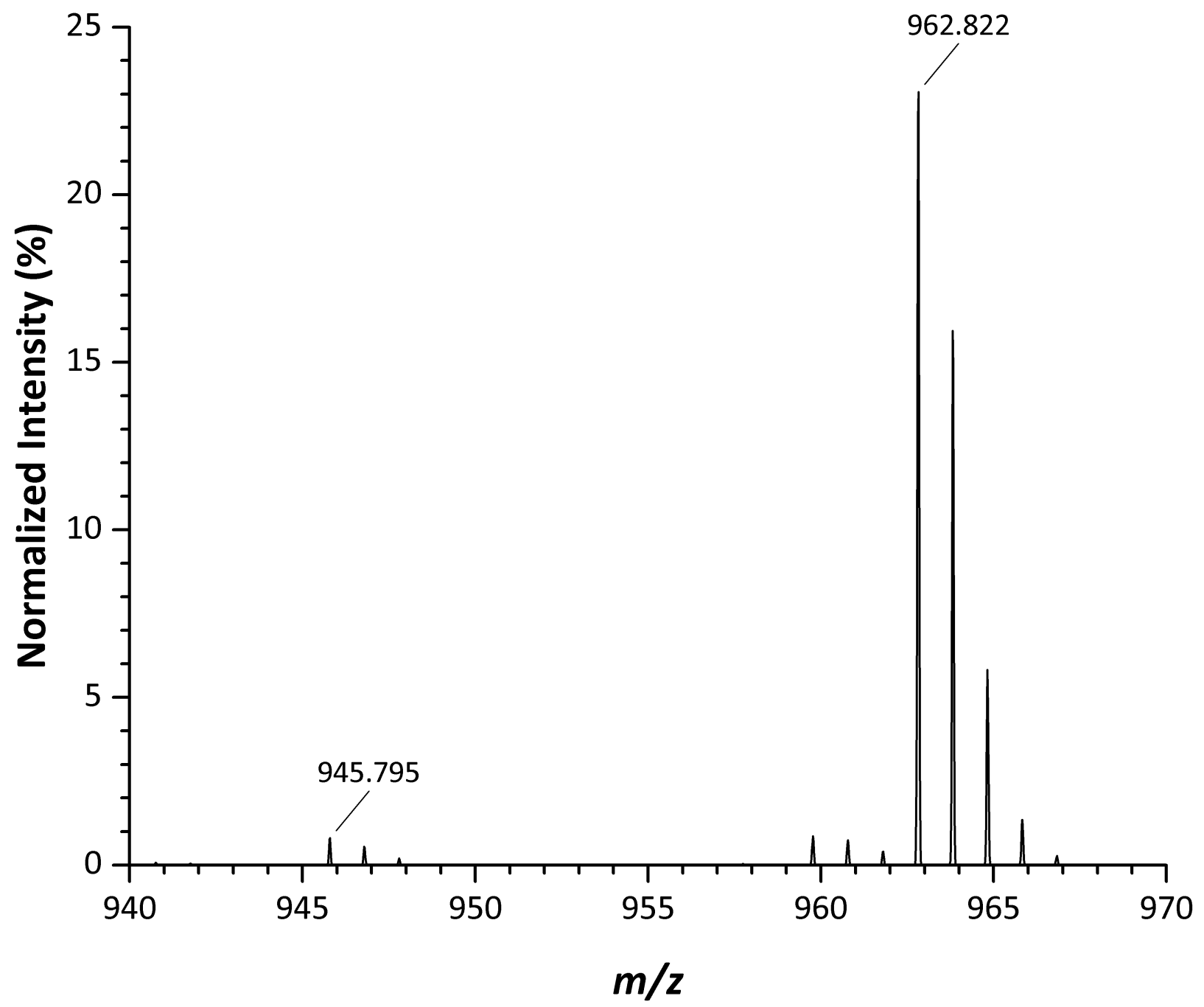


Figure S6. Full scan mass spectrum of suspect THC and VEA-containing sample (same spectrum as Figure 5a). Peaks are putatively assigned as above, except for $m / z 787.627$ (see Figure S7).

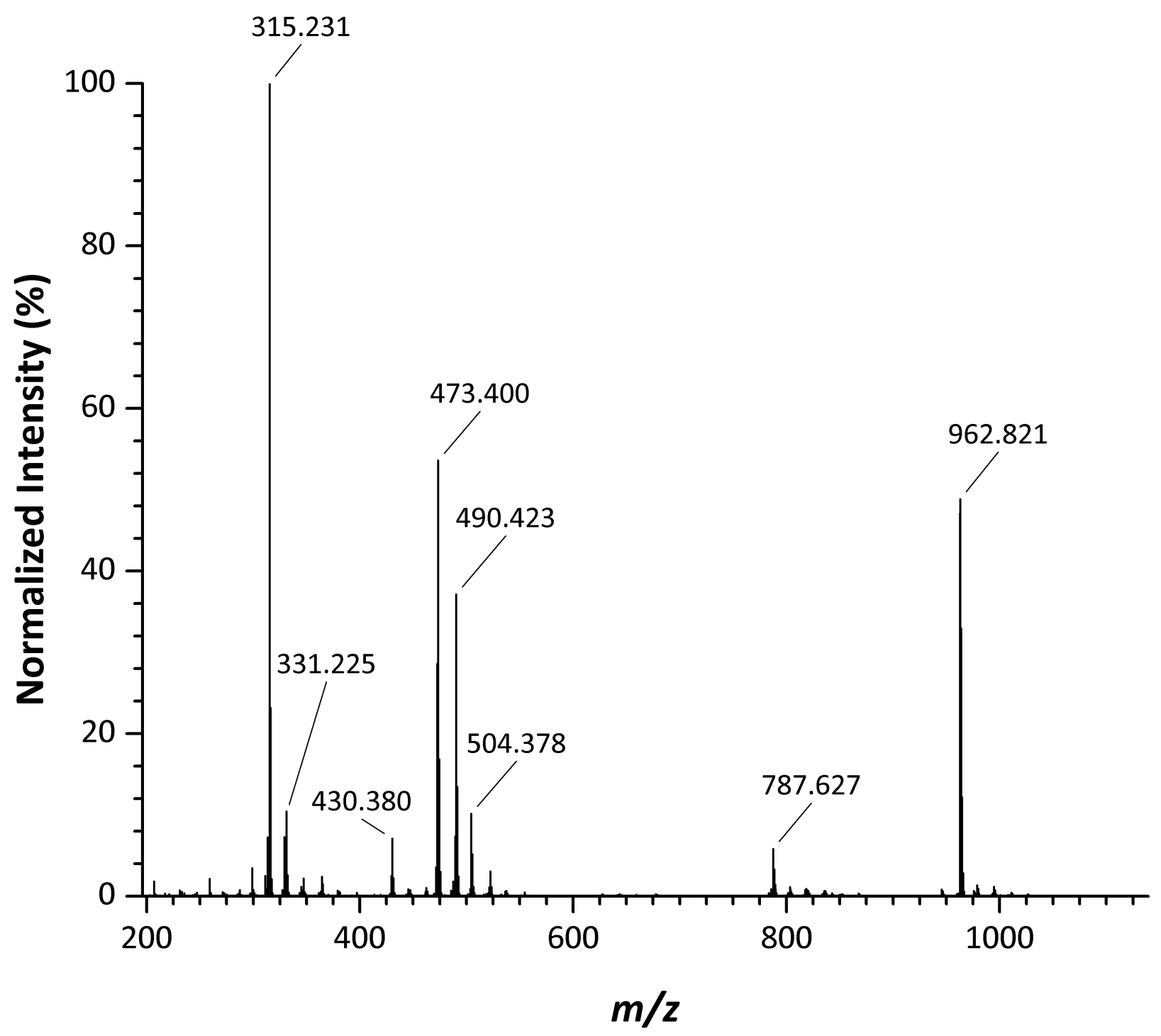


Figure S7. Spectrum from Figure S6 enlarged over the range $m / z, 780-825$. The peaks are putatively assigned as follows: $m / z$ 787.627, $[\mathrm{THC}+\mathrm{VEA}+\mathrm{H}]^{+} ; \mathrm{m} / z$ 803.622, [THC+VEA+H+O$]^{+} ; \mathrm{m} / z$ 818.629, $\left[\mathrm{THC}+\mathrm{VEA}+\mathrm{O}_{2}\right]^{+}$.

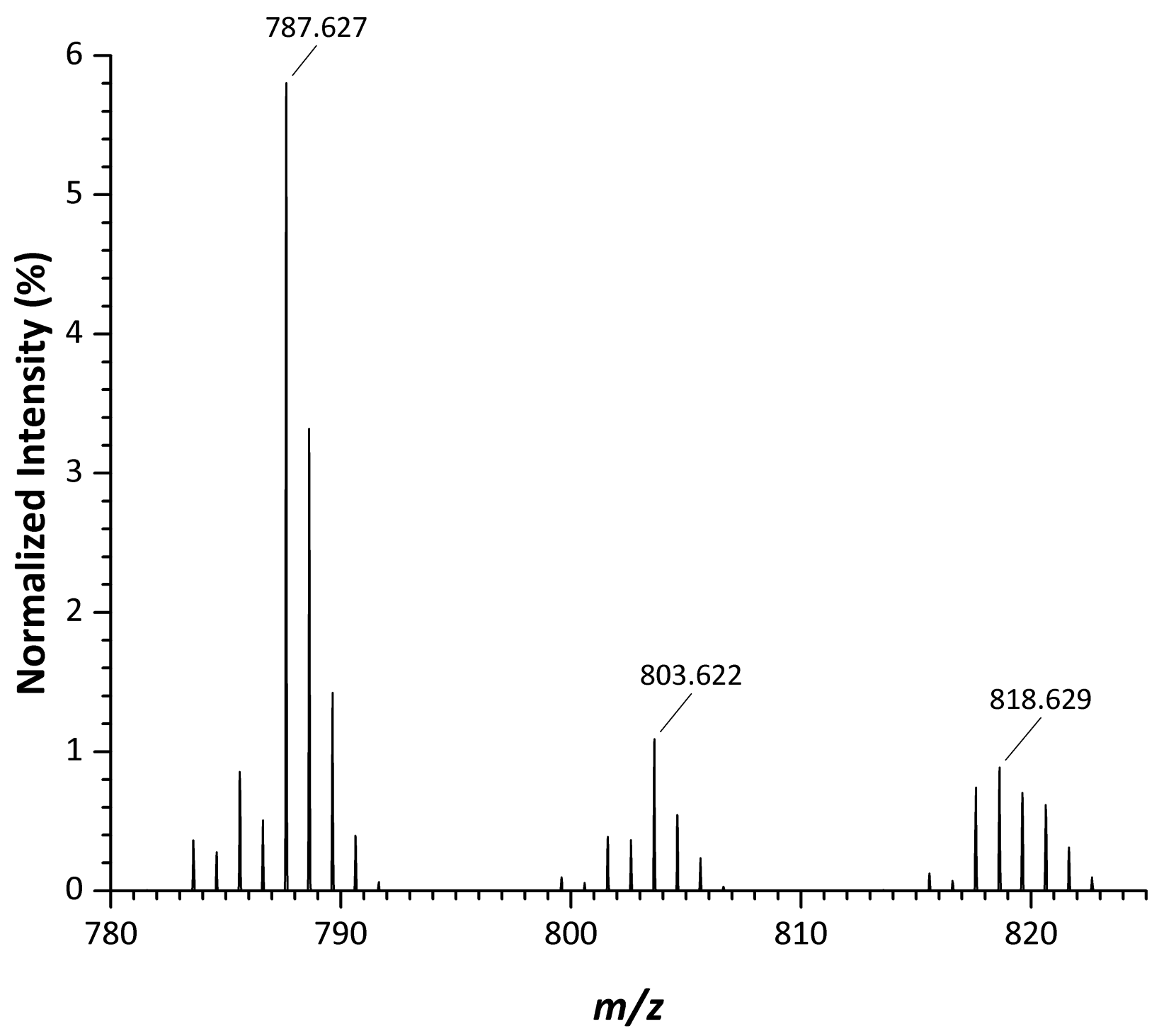


Figure S8. MS/MS spectra obtained with collision energy of $30 \mathrm{eV}$ and precursor isolation width of \pm 0.5 $\mathrm{Da}$ : a) precursor is $[\mathrm{VEA}+\mathrm{H}]^{+}$; b) precursor is $[\mathrm{THC}+\mathrm{VEA}+\mathrm{H}]^{+}$. The spectrum in b) shows that the THC+VEA ion dissociates into THC ( $m / z 315.232$, cf. Figure S2) and VEA $(m / z 473.395$, cf. Figure S4, and $m / z 431.383$ and 207.101, cf. spectrum a) below).

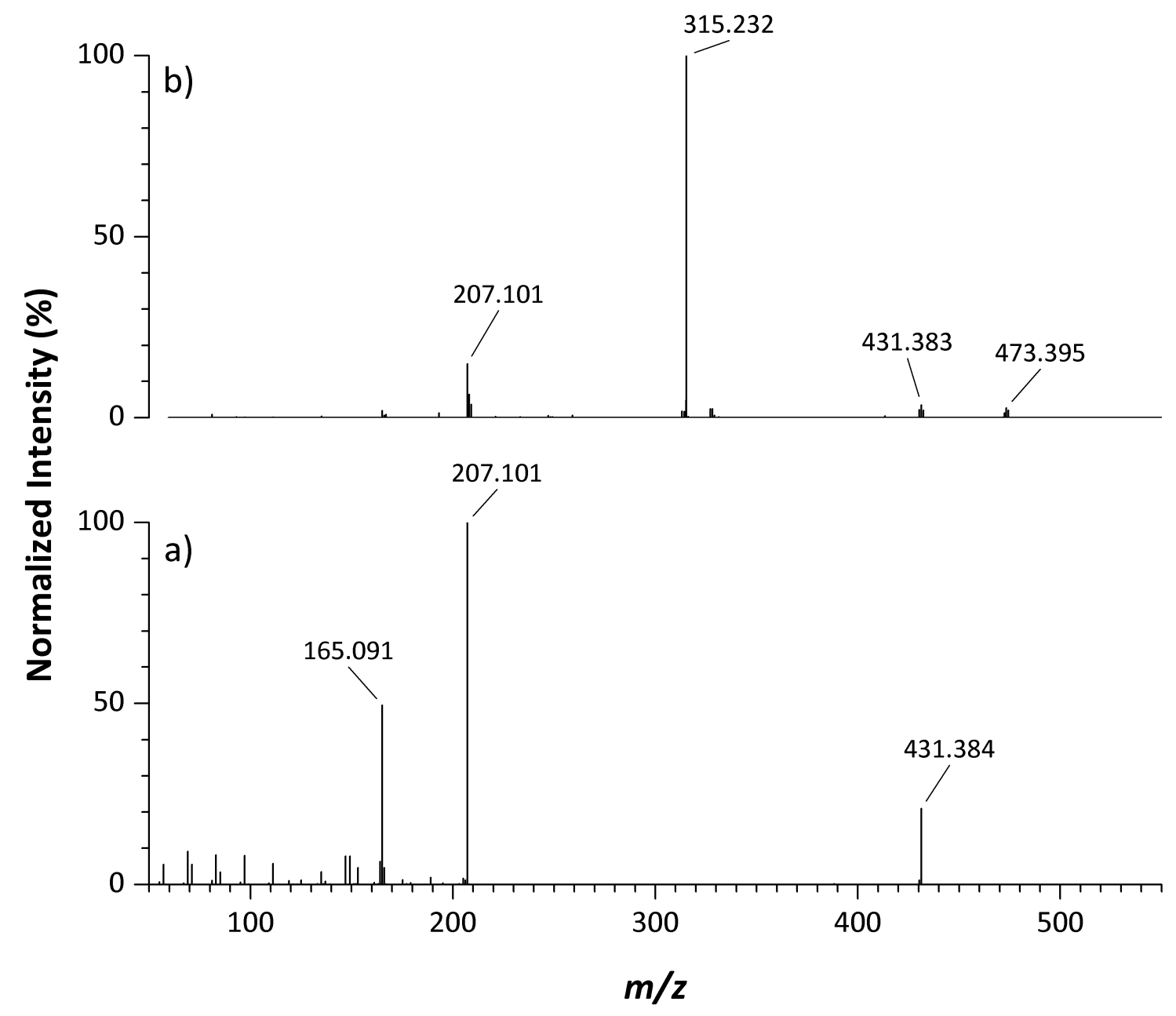


Figure S9. Full scan mass spectrum of aerosolized suspect THC and VEA-containing sample (same spectrum as Figure 5d). Peaks are assigned as above.

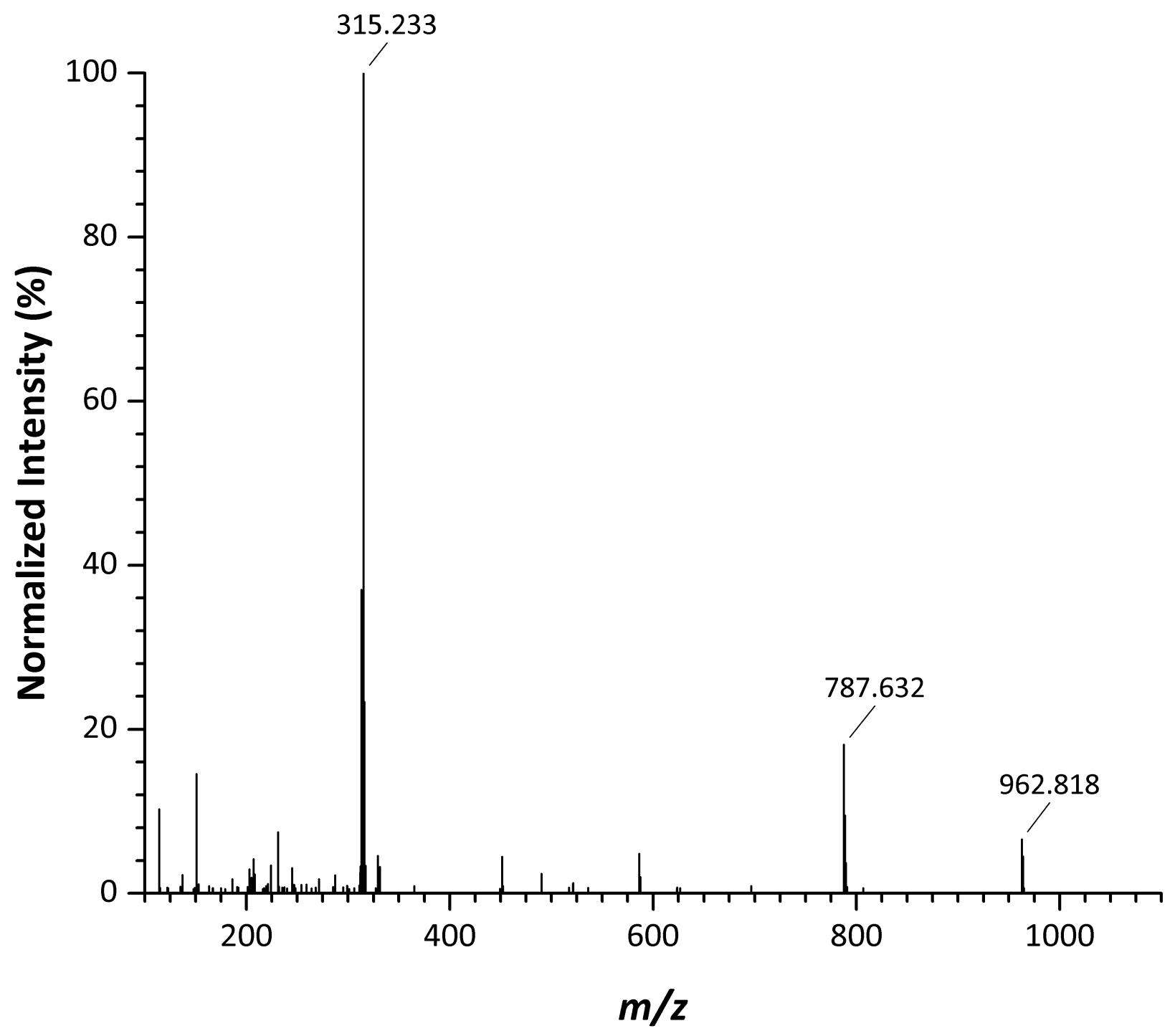


Figure S10. Spectrum from Figure $S 9$ enlarged over the range $m / z 780-825$. The peak assignment is the same as Figure $\mathrm{S} 7\left(\mathrm{~m} / z, 787.627,[\mathrm{THC}+\mathrm{VEA}+\mathrm{H}]^{+}\right.$; additionally labeled peaks are isotopes of this complex).

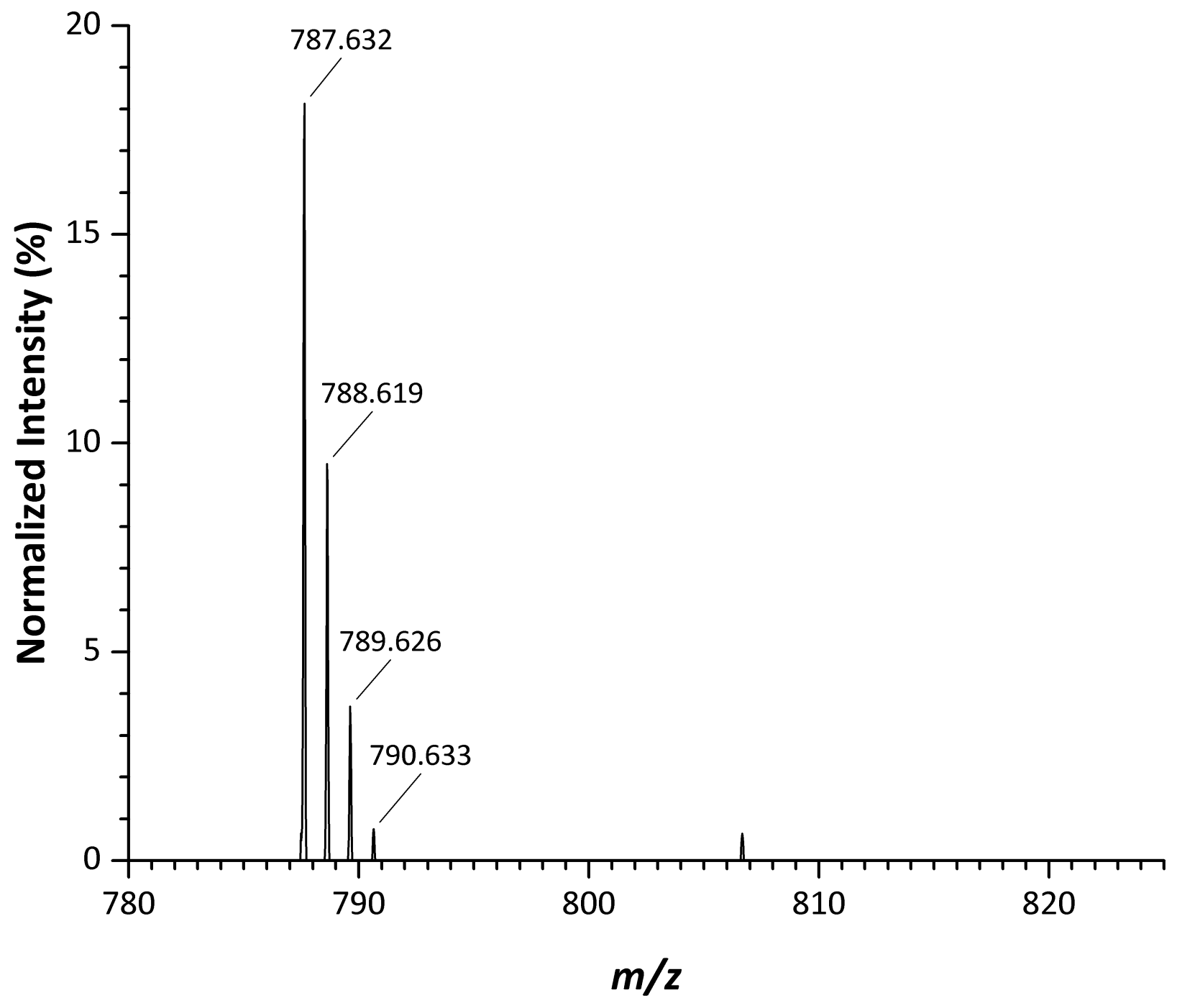

